\title{
Assessment of Post-Stroke Biceps Brachialis Muscle Stiffness by Shear-Wave Elastography: a Pilot Study
}

\author{
P. D. Analan ${ }^{1}$, H. Ozdemir ${ }^{2}$ \\ 1 Department of Physical Medicine and Rehabilitation, School of Medicine, Baskent University, Adana, Turkey \\ 2 Department of Radiology, Baskent University Faculty of Medicine, Adana, Turkey
}

\author{
CORRESPONDING AUTHOR: \\ Pinar Doruk Analan \\ Department of Physical Medicine and \\ Rehabilitation \\ School of Medicine \\ Baskent University \\ Adana Dr. Turgut Noyan Teaching \\ Medical Research Center \\ Dadaloglu Mh \\ 01250, Adana, Turkey \\ E-mail: doruk.pinar@gmail.com
}

\section{DOI:}

10.32098/mltj.03.2020.26

LEVEL OF EVIDENCE: 3B

\begin{abstract}
SUMMARY
Objectives. Spasticity following stroke tend to increase muscle stiffness. Recent clinical measures of post-stroke biceps brachialis muscle spasticity are subjective. We aimed to measure post-stroke biceps brachialis muscle stiffness quantitatively by using shearwave elastography (SWE).

Methods. This prospective study included 24 post-stroke patients with unilateral biceps brachialis muscle spasticity. The Modified Ashworth Scale of the biceps muscle, Brunnstrom stages of the upper extremity of the patients were evaluated as the clinical outcomes. Biceps brachialis muscle stiffness was compared among affected and non-affected upper extremities by SWE. The correlations between SWE findings and clinical outcomes were analyzed.

Results. Shear Wave Velocity $(S W V)$ on the spastic side did not show any significant differences from those on the non-spastic side $(\mathrm{p}>0.05)$. SWV findings were not correlated with clinical outcomes $(r \leq 0.3, p>0.05)$.

Conclusions. Biceps brachialis muscle stiffness was found similar among the affected and non-affected extremities. In addition, $S W V$ was not correlated with clinical outcomes. SWE may not be helpful in detecting the changes in biceps muscle stiffness following stroke.
\end{abstract}

\section{KEY WORDS}

Elastography; spasticity; biceps brachialis muscle; modified Ashworth Scale.

\section{INTRODUCTION}

Spasticity is determined as a velocity-dependent increase in muscle tone and increased resistance to passive movement. It can affect daily living activities, such as mobility, transferring, toileting, and dressing. Also, it may cause pain, contracture, deformity, and limitations on the range of motion (ROM), function and muscle strength (1-4). Muscle hardness may increase with post-stroke spasticity $(5,6)$.

The Modified Ashworth Scale (MAS) is the most commonly accepted clinical spasticity assessment method (1). Several studies in the literature have assessed its validity and reliability (7-11). However, these studies have emphasized that MAS can not detect small changes in muscle spasticity $(9,12)$. Although widely used, the MAS can not evaluate muscle stiffness which has the potential to be related to muscle function (13). Therefore, a non-invasive radiological technique for the quantifying stiffness of the muscles may be useful.
Ultrasound (US) elastography has been shown to assess muscle architectural and mechanical alterations $(14,15)$.

Elastography is a recently developed US-based method to evaluate tissue stiffness. Strain (compression) elastography and shear-wave elastography (SWE) are the two common elastography techniques in clinical practice. Strain elastography produces an image based on the displacement of the tissue from an external or patient source. Point-SWE using acoustic radiation force impulse (ARFI), imaging is a new technique enabling quantitative analysis of tissue elasticity without compression. In ARFI-Imaging, the acoustic pulses generate localized tissue displacements and the displacements cause lateral shear wave propagation which is tracked using laterally positioned US tracking beams. The shear wave velocity $(S W V)$ of the tissue can be reconstructed by estimating the maximum displacement at each lateral location. The shear wave propagation velocity is proportional 
to the square root of tissue elasticity. By SWE, shear wave velocity is expressed in meters per second (16-18).

SWE has been used in studies searching patients with neurological disorders including Parkinson's disease and cerebral palsy (CP), as well as in studies on the effects of dynamic exercise on muscles $(15,19,20)$. Previously reported studies showed that elastography is feasible in the quantitative assessment of spastic biceps brachii muscle $(21,22)$. Herein, we aimed to evaluate the biceps brachialis muscle by SWE and to analyze the correlation of stroke-related outcomes with elastography measurements.

\section{MATERIALS AND METHODS}

This study was approved by the Baskent University Institutional Review Board and Ethics Committee (number of the project: KA16/149) and supported by Institutional Research Fund. Written informed consent was obtained from all subjects before the study. Power analysis measured before the ethics committee application and biostatistics preliminary evaluation revealed that 24 patients should be included in the study.

24 post-stroke patients with biceps brachialis muscle spasticity above 18 years old were evaluated for the present study. Exclusion criteria were; bilateral and multiple stroke attacks healed with sequelae; anti-spastic injections in the last 6 months; established contracture of the elbow; previous treatment with oral or intramuscular anti-spastic treatment medications, intrathecal baclofen, or surgery for spasticity; and other neurological or muscular diseases. Also, subjects who underwent arm and shoulder surgeries were excluded from the present study.
Immediately before performing SWE, clinical outcomes were evaluated by a single physiatrist with 16 years of experience in neurologic rehabilitation.

\section{CLINICAL OUTCOME MEASURES}

\section{Modified Ashworth Scale (MAS)}

The MAS is most commonly used tool of spasticity and includes these categories: : 0 (MAS 0), normal muscle tone; 1 (MAS 1), minimal increased in muscle tone; 2 (MAS 1+), minimal increased in muscle tone that seen throughout less than half of the ROM; 3 (MAS 2), more marked increase in muscle tone through most of the ROM; 4 (MAS 3), considerable resistance, difficulty of passive movement; 5 (MAS 4), rigid elbow flexion. ${ }^{23}$

\section{Brunnstrom motor recovery stages}

Brunnstrom motor recovery stages (BS) of the upper extremity was used in this study (24). BS comprises six stages: stage I, flaccidity, no active movement on the affected side; stage II, appearance of spasticity, muscles begin involuntary, abnormal, small movement with synergy; stage III, spasticity increases and synergy arising maximum level, muscles begin voluntary and synergic contractions; stage IV, decreased spasticity, movement is seen voluntary, more complex and non-synergic features; stage V, spasticity decreased and minimal, the patient has isolated active movement; and stage VI, no spasticity, muscle tone is normal, all of the isolated active movement is seen. A higher stage of BS represents better recovery (25).

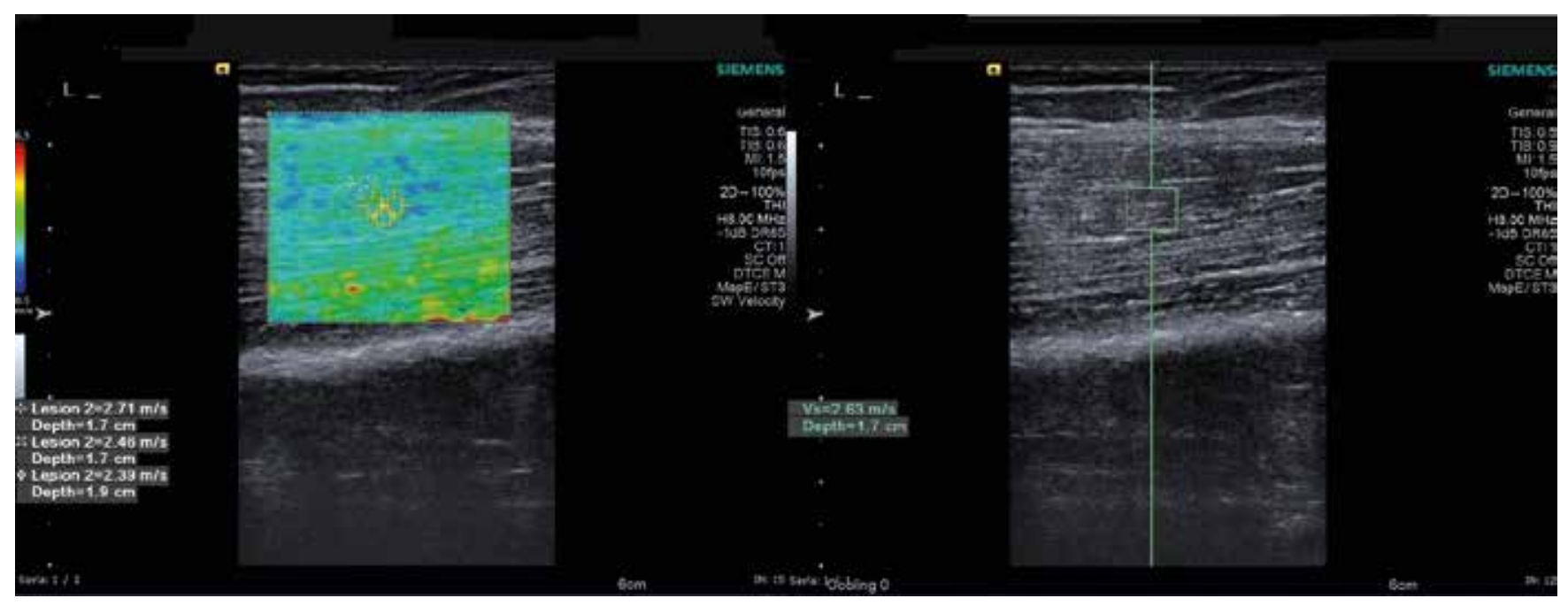

Figure 1. 45 years old patient with right sided upper limb spasticity following stroke. SWV of the spastic biceps muscle measured by VTIQ method (right) and VTO method (left) are shown. 


\section{Shear Wave Elastography (SWE)}

US and SWE examinations were performed using a US system (Acuson S 2000; Siemens, Erlangen, Germany). SWE was performed using a probe with an L9-4 linear array. SWE was performed with the patient in a sitting position in front of an examination bed. The patient was asked to keep their elbow in extension and their hand in a pronated position to keep the biceps muscles relaxed. The affected arm was positioned with the wrist in a rest position. All patients were requested to remain as relaxed as possible throughout the testing (approximately 1-2 minutes). Evaluations were repeated for the unaffected side in the same manner.

A standard US examination was initially performed to view the biceps muscle in the axial plane. Measurements were performed from the belly point of the muscle while the muscle was seen on the longitudinal plane (figure 1). All patients were evaluated by both VTQ and VTIQ methods. Scanning was repeated if any movement or muscle contraction occurred during SWE. Image quality was assessed using quality maps produced by the US system. The image having the highest quality map was used to measure SWV. A rectangular electronic box-shaped region of interest (ROI) was used for measurements. At least three boxes were set at the mid-depth of the muscle by VTIQ. Maximum SWVs were recorded. As measured by SWE, faster velocity refers to greater stiffness (hardness) and lower velocity indicates less stiffness (softness).

\section{STATISTICAL ANALYSIS}

The statistical package SPSS software (Version 17.0, SPSS Inc., Chicago, IL, USA) was used for statistical analysis Normal continuous variables were described as the mean \pm standard deviation ( $p>0.05$ in Kolmogorov-Smirnov test or Shapira-Wilk $[\mathrm{n}<30]$ ) and variables that were not normal were described as the median. The Student T-test was used to compare groups for normally distributed data and the Mann Whitney U test for not normally distributed data. The Pearson's correlation test was used for correlation analyses. The correlation coefficients were interpreted either excellent $r \geq 0.91$; good $0.90 \geq r \geq 0.71$; fair $0.70 \geq r \geq 0.51$; weak $0.50 \geq r \geq 0.31$; or little or none $r \leq 0.3$. Values of $p<0.05$ were considered statistically significant.

Table I. Clinical characteristics of the study population.

\begin{tabular}{ll}
\hline Characteristics & Value \\
\hline Age (years) * & $57.46 \pm 10.27$ \\
\hline Gender (Females/ Males), (n) & $14 / 10$ \\
\hline Time since stroke, months* & $23.08 \pm 26.06$ \\
\hline Body mass index, $\mathrm{kg} / \mathrm{m}^{2} *$ & $27.04 \pm 7.35$ \\
\hline Paretic side, Right/left, $(\mathrm{n})$ & $9 / 15$ \\
\hline Stroke type, $(\mathrm{n})$ & 18 \\
\hline Ischemic & 4 \\
\hline Hemorrhagic & 2 \\
\hline Hemorrhagic transformation following ischemic stroke & \\
\hline
\end{tabular}

*: mean \pm standard deviation

Table II. Clinical outcomes of study population, (n:24).

Characteristics

n

Brunnstrom's Stages of Motor Recovery of the upper extremity

\begin{tabular}{lll}
\hline Stage 2 & 7 \\
\hline Stage 3 & 9 \\
\hline Stage 4 & 5 \\
\hline Stage 5 & 3 \\
\hline Spasticity degree of biceps brachialis measured using the Modified Ashworth Scale & 8 \\
\hline Stage $1+$ & 13 \\
\hline Stage 2 & 3 \\
\hline Stage 3 & \\
\hline
\end{tabular}


Table III. Comparisons of Shear-Wave Elastography measurements of biceps brachialis muscle, (m/s), (mean \pm standard deviation).

\begin{tabular}{lcc}
\hline Characteristics & Value & p \\
\hline Shear Wave Velocity (VTIQ) & & 0.73 \\
\hline Spastic side & $3.22 \pm 1.2$ & \\
\hline Non-spastic side & $3.15 \pm 0.91$ & 0.74 \\
\hline Shear Wave Velocity (VTQ*) & $2.63 \pm 1.06$ & \multirow{2}{*}{ Spastic side } \\
\hline Non-spastic side & $2.95 \pm 0.185$ &
\end{tabular}

*: Virtual Touch Imaging Quantification

**: Virtual Touch Quantification

\section{RESULTS}

The study population consisted of 10 male and 14 female patients with a mean age of $57.46 \pm 10.27$ years. The major etiology of stroke was hypertension in 12 patients, followed by diabetes mellitus in 2 and a history of mitral valve surgery in 1 . Multifactorial etiologies were responsible for 5 patients and the etiology was unknown in 4. Clinical features are noted in table I. BS and MAS scores are summarized in table II.

16 of the patients $(66.6 \%)$ had stage 2 and 3 disease whereas 8 patients $(33.4 \%)$ had stage 4 and 5 disease. 13 of the patients had $(54.2 \%)$ score 2 disease by MAS.

The SWV findings were statistically similar among the groups. Comparisons of SWV measurements are categorized in table III.

There were not any correlations between the both SWV (measured both VTIQ and VTQ methods) of the biceps brachialis muscle with the duration of a stroke, MAS, or BS scores $(r \leq 0.3, p>0.05)$.Pearson correlation coefficients were as follows for VTIQ measurements: duration of stroke $(\mathrm{r}=-0.18)$, MAS score $(\mathrm{r}=0.0073)$ and BS score $(\mathrm{r}=0.056)$. Pearson correlation coefficients were as follows for VTQ measurements: duration of stroke $(\mathrm{r}=-0.196)$, MAS score $(\mathrm{r}$ $=-0.048$. $)$ and BS score $(\mathrm{r}=0.13)$.

\section{DISCUSSION}

This study showed that post-stroke biceps brachialis muscle stiffness was not different from the non-spastic side. Also, SWV findings were not correlated with clinical spasticity and motor recovery stage evaluations. We believe that the inactivity and disuse of the muscles may lead to muscle atrophy. In our study, the standard deviation of the duration of stroke was high as a result; the difference in muscle pathological changes including muscle degeneration could widely vary among our study population. Thus, muscle atrophy may neutralize the effects of muscle stiffness.

In the literature, there are some studies analyzing the effects of some neurological disorders on muscles using elastogra- phy. Parkinson's disease was reported to cause increased biceps muscle stiffness when compared with healthy subjects (15).

Moreover, Kesikburun et al. (2) found a significant increase of post-stroke gastrocnemius muscle stiffness compared with the non-spastic side by strain elastography. In addition, a recent study reported that medial gastrocnemius muscle stiffness of patients with $\mathrm{CP}$ was higher than that of healthy children using SWE (13).

Another study including children with $\mathrm{CP}$ proposed that elastography can detect the stiffer areas in the spastic muscles and guide the description of optimal injection sites for botulinum toxin therapy (19).

Not only the neurological disorders but also posture, exercise, gender or anatomical properties were reported to affect the muscle stiffness. Nordez et al. (26). reported that stretching of the ankle plantar flexors increases the gastrocnemius muscle elasticity. Also, biceps brachii muscle stiffness measured by SWE can also be affected by the flexion or extension posture of the elbow and gender of the patients (27). The posture of the extremities, stretching degree of the tendons and muscle contractions can, therefore, be considered to potentially affect elastography measurements. It may be difficult to standardize all factors among the studies. Another study showed a reduction in the strain ratio after exercise (20). Due to the difficulty in controlling all parameters during examinations, differences in measurements may depend on the complexity of muscle function and anatomy. The limited number of patients may be considered the first limitation of our study. Also, we could not categorize the study population according to MAS or BS scores.

The level of evidence of the study is $3 \mathrm{~B}$, so randomized controlled trials are needed (28).

\section{CONCLUSIONS}

In conclusion, SWE seems not an applicable tool for the evaluation of changes in muscle stiffness in the spastic biceps brachialis muscle following stroke. 


\section{AUTHOR CONTRIBUTIONS}

PDA conceived the study. PDA and HO collected the data, conducted statistical analysis and wrote the first draft of the manuscript. All authors reviewed and edited the manuscript and approved the final version of the manuscript.

\section{ETHICS}

This study was approved by Baskent University Institutional Review Board and Ethics Committee (number of the project: KA16/149) and supported by Institutional Research Fund.

\section{CONFLICT OF INTERESTS}

The authors declare that they have no conflict of interests.

\section{REFERENCES}

1. Kaku M, Simpson DM. Spotlight on botulinum toxin and its potential in the treatment of stroke-related spasticity. Drug Des Devel Ther.2016;10:1085-1099.

2. Kesikburun S, Yaşar E, Adıgüzel E, Güzelküçük Ü, Alaca R, Tan AK. Assessment of Spasticity With Sonoelastography Following Stroke: A Feasibility Study. PM R.2015;7(12):1254-60.

3. Brainin M, Norrving B, Sunnerhagen KS, Goldstein LB, Cramer SC, Donnan GA, et al. International PSS Disability Study Group: Poststroke chronic disease management: Towards improved identification and interventions for poststroke spasticity-related complications. Int J Stroke. 2011;6(1): 42-46.

4. Sommerfeld DK, Eek EU, Svensson AK, Holmqvist LW, von Arbin MH.. Spasticity after stroke: Its occurrence and association with motor impairments and activity limitations. Stroke. 2004;35(1): 134-139.

5. Rydahl SJ, Brouwer BJ. Ankle stiffness and tissue compliance in stroke survivors: a validation of myotonometer measurements. Arch Phys Med Rehabil. 2004;85(10):1631-1637.

6. Leonard CT, Stephens JU, Stroppel SL. Assessing the spastic condition of individuals with upper motorneuron involvement: validity of the myotonometer. Arch Phys Med Rehabil. 2001;82(10): 1419-1420.

7. Brashear A, Zafonte R, Corcoran M, et al. Inter- and intrarater reliability of the ashworth scale and the disability assessment scale in patients with upper-limb poststroke spasticity. Acad Am J Phys Med Rehabil. 2002;83(10):1349-1354.

8. Pandyan AD, Johnson GR, Price CI, Curless RH, Barnes MP, Rodgers H. A review of the properties and limitations of the ashworth and modified ashworth scales as measures of spasticity. Clin Rehabil. 1999; 13(5): 373-383.

9. Mehrholz J, Wagner K, Meissner D, Grundmann K, Zange C, Koch R, Pohl M. Reliability of the modified tardieu scale and the modified ashworth scale in adult patients with severe brain injury: a comparison study. Clin Rehabil. 2005;19(7):751-759.

10. Biering-Sorensen F, Nielsen JB, Klinge K. Spasticity-assessment: a review. Spinal Cord. 2006;44(12):708-722.

11. Abolhasani H, Ansari NN, Naghdi S, Mansouri K, Ghotbi N, Hasson S. Comparing the validity of the Modified Modified Ashworth Scale (MMAS) and the Modified Tardieu Scale (MTS) in the assessment of wrist flexor spasticity in patients with stroke: protocol for a neurophysiological study. BMJ Open. 2012;2(6).
12. Seth N, Johnson D, Taylor GW, Allen OB, Abdullah HA. Robotic pilot study for analysing spasticity: clinical data versus healthy controls. J Neuroeng Rehabil. 2015;12:109.

13. Kwon DR, ParkGY, Lee SU, Chung I. Spastic cerebral palsy in children: dynamic sonoelastographic findings of medial gastrocnemius. Radiology. 2012;263(3): 794-801.

14. Lee SS, Spear S, Rymer WZ. Quantifying changes in material properties of stroke-impaired muscle. Clin Biomech (Bristol, Avon). 2015;30(3): 269-275.

15. Du LJ, He W, Cheng LG, Li S, Pan YS, Gao J. Ultrasound shear wave elastography in assessment of muscle stiffness in patients with Parkinson's disease: A primary observation. Clin Imaging. 2016;40(6):1075-1080.

16. Nightingale K, Soo MS, Nightingale R, Trahey G. Acoustic radiation force impulse imaging: in vivo demonstration of clinical feasibility. Ultrasound Med. Biol. 2002;28(2): 227-235.

17. Dahl JJ, Palmeri ML, Nightingale KR, et al. 4K-5 Shear Wave Velocity Estimation Using Acoustic Radiation Force Impulsive Excitation in Liver In Vivo. 2006 IEEE Ultrason. Symp, IEEE,2006: pp. 1156-1160.

18. Sarvazyan AP, Rudenko OV, Swanson SD, Fowlkes JB, Emelianov SY. Shear wave elasticity imaging: a new ultrasonic technology of medical diagnostics. Ultrasound Med. Biol. 1998;24(9):1419-1435.

19. Vasilescu D, Vasilescu D, Dudea S, Botar-Jid C, Sfrângeu S, Cosma D.Sonoelastography contribution in cerebral palsy spasticity treatment assessment, preliminary report: a systematic review of the literature apropos of seven patients. Med Ultrason. 2010;12(4):306-310.

20. Yanagisawa O, Niitsu M, Kurihara T, Fukubayashi T. Evaluation of human muscle hardness after dynamic exercise with ultrasound real-time tissue elastography: a feasibility study. Clin Radiol. 2011;66(9):815-819.

21. Gao J, He W, Du LJ, Chen J, Park D, Wells M, Fowlkes B, O'Dell M. Quantitative Ultrasound Imaging to Assess the Biceps Brachii Muscle in Chronic Post-Stroke Spasticity: Preliminary Observation. Ultrasound Med Biol. 2018;44(9):1931-1940.

22. Wu CH, Ho YC, Hsiao MY, Chen WS, Wang TG. Evaluation of Post-Stroke Spastic Muscle Stiffness Using Shear Wave Ultrasound Elastography. Ultrasound Med Biol.2017;43(6):1105-1111.

23. Bohannon RW, Smith MB. Interrater reliability of a modified Ashworthscale of musclespasticity. Phys Ther. 1987;67(2):206-207.

24. Brandstater ME.Stroke rehabilitation. In: DeLisa JA, ed: Rehabilitation Medicine principles and practice, Philadelphia, Lippincott Raven Publishers, 1998; 1165-1189.

25. Kuptniratsaikul V, Kovindha A, Suethanapornkul S, et al. Motor recovery of stroke patients after rehabilitation: one-year followup study. Int J Neurosci. 2017;127(1):37-43.

26. Nordez A, Gennisson JL, Casari P, Catheline S, Cornu C.Characterization of muscle belly elastic properties during passive stretching using transient elastography. J Biomech. 2008;41(10): 2305-2311.

27. Chen J, O'Dell M, He W, Du LJ, Li PC, Gao J. Ultrasound shear wave elastography in the assessment of passive biceps brachii muscle stiffness: influences of sex and elbow position. Clin Imaging. 2017;45:26-29.

28. Padulo J, Oliva F, Frizziero A, Maffulli N. Muscles, Ligaments and Tendons Journal - Basic principles and recommendations in clinical and field Science Research: 2018 update. MLTJ 2018; 8(3): $305-307$. 